\title{
Survey on Detection and Classification of Plant Leaf Disease in Agriculture Environment
}

\author{
Prof. Patil Ashish ${ }^{1}$, Patil Tanuja ${ }^{2}$ \\ Professor, Department of Computer Science and Engineering, AGTI'S DACOE Karad, India ${ }^{1}$ \\ Student, Department of Computer Science And Engineering, AGTI'S DACOE Karad, India ${ }^{2}$
}

\begin{abstract}
In the agriculture environment, the detection and classification of the plant disease system plays very important role. In this first leaf image is captured and uploaded to the system where this image is compared with another image which is stored in the database. Comparison is take place with the help of algorithm which is named as content based histogram algorithm. For detecting the leaf disease image processing is used. The Image processing consist color extraction and then affected area is compare. The system helps to initial precautionary measures. If proper care is not taken then it will affected on quality, quantity and finally on productivity. This paper presents survey on different detection and classification techniques for plant diseases and also image processing technique which is used for automatic, fast and accurate detection as well as classification of plant leaf diseases.
\end{abstract}

Keywords: K-Mean's clustering, Otsu Method, Fuzzy logic, Artificial Neural Network, Probabilistic Neural Network, Super Vector Machine, Plant leaf diseases.

\section{INTRODUCTION}

As we know, India is one of the agriculture based country which will help to increase the nation growth. Most of the people are depends on the agriculture for their live hood. So loss of crops from plant disease may result in hunger and starvation. Leaves are important because they are the primary source of photosynthesis, which is how plants feed themselves. Control of plant disease is a crucial to the reliable production of food. It is very difficult to the farmers to diagnose the disease only with the help of observation. Identification of diseases of plant leaf is a very important and challenging task. To overcome this, we are developing a system which will help to detect and classify the plant leaf disease in agriculture. Research in agriculture is aimed towards increasing food quality and productivity with increased profit. Farmers have wide range of diversity to select fruit and vegetable crop. Advanced computing system to identify the diseases using infected images of various leaf spots. Such crops caused by fungi, bacteria, viruses. Diseases management is difficult task. Huge number of disease found on leafs. Hence, detection of that disease on particular plant with their solution and also with some preventation technique is very necessary.

The existing method for diseases detection on different plant is simply naked eye observation with the help of experts through which diseases identification done but, this requires continuous monitoring which is very time consuming process and quite expensive in case of large farms. In some countries,

At the same time when detection is done with eye observation, farmers don't have proper idea and facilities that they can contact to experts due to which consulting experts cost is very high and it is time consuming.
By using histogram and content based Image Processing algorithm with building the useful web service or tool for "Detection and classification of plant leaf diseases. Plant leaf disease classifications have wide applications in various fields such as in biological research, in Agriculture etc. In modern agricultural field, various computational methods have been developed to help farmers to identify diseases on plant and to monitor the proper growth of their crops. Therefore identification of plants, leaves, stems and finding out the diseases, percentage of the disease incidence, symptoms of the disease attack, plays a key role in successful cultivation of plants. Hence there is scope for working on development of innovative, efficient and fast interpreting algorithms which will help to detecting diseases. The proposed system is a software solution for automatic detection and computation of texture statistics for plant leaf diseases.

\section{LITERATURE SURVEY}

Savita N. Ghaiwat, Parul Arora presents and K-nearest neighbor (KNN) method for predicting the class of test example. This is very time consuming method. Also they used Support vector machine (SVM) techniques which have more accuracy in prediction. Another technique they used is Self Organization Map and Probabilistic Neural Network. It requires large storage space. One more desirable techniques they used known as Fuzzy Logic.[1]

According to the Renuka Rajendra Kajale, she introduces the different application of texts sure analysis in detecting the plant disease. For detecting the plant disease she used image Processing technique. In this paper classification is achieved with the help of HSI transformation. [2] 
IARJSET

This paper consists of two phases to detecting and This paper gives the executed results on different diseases recognizes the plant leaf disease. First content based image classification techniques that can be used for plant leaf retrieval technique is used to identify the disease, and disease detection. For detection of plant leaf disease they finally classification of diseases is performed with the help use the HSV features and SVM classifier.[5]

of K-Means. Both of this methods are very useful to An Application of texture analysis is detecting the plant predict the plant disease.[3]

leaf disease has been introduced in this paper. They use the image processing techniques for the analysis.[6]

In this paper different image processing techniques are In this paper they use the data mining technique which described which are used for several plant species that consist of applying data analysis and discovery algorithm have been used for detecting plant diseases.[4] that produce particular pattern over the data.[7]

\section{TABLE I DISEASE CLASSIFICATION TECHNIQUES}

\begin{tabular}{|c|c|c|c|c|}
\hline Sr. No. & Techniques & Description & Advantages & $\begin{array}{c}\text { Disadvantages } \\
\end{array}$ \\
\hline 1 & $\begin{array}{l}\text { K-Nearest } \\
\text { Neighboring }\end{array}$ & $\begin{array}{l}\text { Calculate the minimum } \\
\text { distance between the } \\
\text { points. }\end{array}$ & $\begin{array}{l}\text { Easy to implement and } \\
\text { quite good in result. }\end{array}$ & $\begin{array}{l}\text { Slow learner, not robust to the } \\
\text { noise data in large training } \\
\text { example. }\end{array}$ \\
\hline 2 & $\begin{array}{l}\text { Super } \\
\text { Vector } \\
\text { Machine } \\
\text { (SVM) }\end{array}$ & $\begin{array}{l}\text { IT Construct Hyper } \\
\text { plane in infinite } \\
\text { dimensional space. }\end{array}$ & $\begin{array}{l}\text { Prediction accuracy is } \\
\text { high, robust } \\
\text { working when training } \\
\text { example contain errors. }\end{array}$ & $\begin{array}{l}\text { Involve long training time, difficult } \\
\text { to understand learned function. } \\
\text { large no. of support vectors used } \\
\text { from the training set to perform } \\
\text { classification task. }\end{array}$ \\
\hline 3 & $\begin{array}{l}\text { Probabilistic } \\
\text { Neural } \\
\text { Network } \\
\text { (PNN) }\end{array}$ & $\begin{array}{l}\text { It work with four layer } \\
\text { structure which } \\
\text { involves distance } \\
\text { calculation, storage of } \\
\text { predictor variable and } \\
\text { comparison of the } \\
\text { votes }\end{array}$ & $\begin{array}{l}\text { Much faster and more } \\
\text { accurate }\end{array}$ & Require large storage space. \\
\hline 4 & Fuzzy Logic & $\begin{array}{l}\text { Use membership } \\
\text { function to convert real } \\
\text { world data value to } \\
\text { membership degree. }\end{array}$ & $\begin{array}{l}\text { High speed, preferable } \\
\text { in limited precision I }\end{array}$ & $\begin{array}{l}\text { Dimensionality (Large no. the } \\
\text { features), Poor performance. }\end{array}$ \\
\hline 5 & $\begin{array}{l}\text { Artificial } \\
\text { Neural } \\
\text { Network } \\
\text { (ANN) }\end{array}$ & $\begin{array}{l}\text { Multilayer Perception } \\
\text { is basic form of ANN } \\
\text { that updates the weight } \\
\text { through basic } \\
\text { propagation. }\end{array}$ & $\begin{array}{l}\text { Good potential with } \\
\text { ability to detect plant } \\
\text { leaf disease. }\end{array}$ & Require more time. \\
\hline
\end{tabular}

\section{Algorithm}

\section{1 .K-Means Clustering:-}

Clustering is the process of partitioning a group of data points into a small number of clusters.

Steps in Algorithm-

1. Determine the initial centroid coordinate.

2. Calculate the distance of each data-point to the centroid.

3. Group the data-points based on their minimum distance. (Find the nearest centroid)

$\mathrm{K}$-means clustering is very efficient and powerful algorithm to handle large data sets. It assists faster image retrieval and also allows the search for most relevant images in large image database. K-means clustering algorithm is skilled in generating correct results for image retrieval problems.
The segmentation is done by using $\mathrm{K}$-means clustering technique. K-Means classify the objects (pixel) based on the set of the features in to k-no. of the classes. Classification done with the help of sum of square of distance between the object. For clustering and classification of diseases on plant the application of medium filter, CIELAB color model, and clustering and texture analysis are formulated.

\section{Otsu Method:-}

After image is segmented by $\mathrm{K}$-means clustering technique, green pixels value of leaf is masked and then removes these green masked pixels and obtained the threshold value of object by Otsu's method.

Otsu's method used to automatically perform clustering based image threshold or, the reduction of a gray level image to a binary image. 
IARJSET

\section{Color Co-Occurrence Method:-}

The RGB images are sets to zero value for converting color co-occurrence technique. Distribution of cooccurring pixel value at given offset is takes place in this method and the features of the leaves are extracted and compared with the corresponding features values stored in the library.

The color co-occurrence texture analysis method is developed through the Spatial Gray-level Dependence Matrices (SGDM). The gray level co-occurrence methodology is a statistical way to describe shape by statistically sampling the way certain gray-levels occur in relation to other gray levels . These matrices measure the probability that a pixel at one particular gray level will occur at a distinct distance and orientation from any pixel given that pixel has a second particular gray level.

\section{DESIGN}

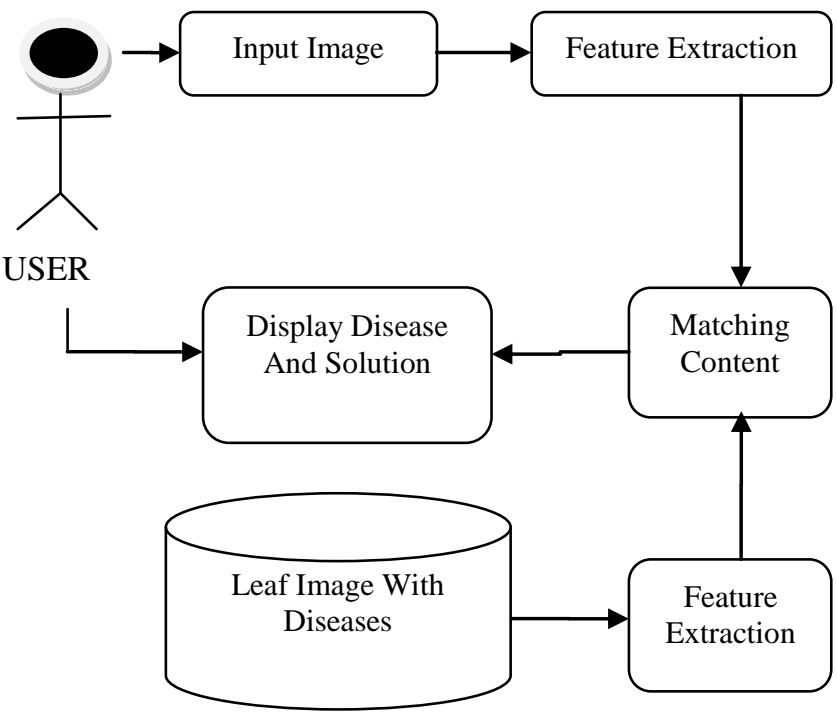

Fig.1. Architecture Diagram

\section{IMAGE PROCESSING}

In agriculture environment, image processing is a advanced technology used to overcome the problems related with all existing techniques of plant disease detection. Image processing provides very fast and more accurate result which help in disease management.

There are five main steps for the detection using image processing are -

1. Image acquisition can be defined as the retrieving of an image using some sources.

2. Image pre-processing improve the image data that suppress undesired distortions.

3. Image segmentation is the process of clustering the image in to no. of parts containing same pixel.

4. Feature extraction extract features that can be used to determine the meaning of a given image.
5. Classification is to correctly predict the value of a designated discrete class variable or attributes.

Advantages of image processing-

1. To detect diseased leaf, stem, fruit.

2. To quantify affected area by disease.

3 . To find shape of affected area.

4. To determine size \& shape of fruits

5. Plant diseases can be identified at early or the initial stage.

\section{CONCLUSION}

The main approach of this system is to recognize the diseases on different plant in agriculture environment where Speed and accuracy are the main characteristics of disease detection. Hence, the extension of this work will focus on developing the advanced algorithms for fast and accurate diseases detection of leaves.

After reviewing all above mentioned techniques and methods we can conclude that there are number of ways by which we can detect disease of plants. Each has some advantages as well as limitations. Therefore, there is scope of improvement in the existing research.

Image processing is a technique which helps to improve all existing research and which gives fast and accurate result of plant diseases.

\section{ACKNOWLEDGMENT}

It is our privilege to acknowledge with deep sense of gratitude to our project guide and our H.O.D Prof. Patil Ashish N. whose supervision, inspiration and valuable discussion has helped us tremendously to complete our project. Their guidance proved to be the most valuable to overcome all the hurdles in the fulfillment of this mega project on "Detection and Classification of Plant Leaf Diseases".

\section{REFERENCES}

[1] Savita N. Ghaiwat, Parul Arora, "Detection and Classification of Plant Leaf Diseases Using Image processing Techniques: A Review" 3,2014.

[2] Renuka Rajendra Kajale, "Detection and Reorganization of Plant Leaf Disease Using Image Processing and Android O.S." MarchApril 2015.

[3] A.S.Deokar, Akshay Pophale, Swapnil Patil, Prajakta Nazarkar, Sukanya Mungase, "Plant Disease Identification using Content Based Image Retrieval Techniques Based on Android System" 2016.

[4] Harshad Shetye, Tejas Rane, Tanmay Pawar, Prof. Anuradha Dandwate" An Analysis of Methodologies For Leaf Disease Detection Techniques" February 2016.

[5] M. RavindraNaik, Chandra Mohan Reddy Sivappagari "Plant Leaf And Disease Detection By Using HSV Features and SVM Classifier" December 2016

[6] S.Ananthi, S. Vishnu "Detection and Classification Of Plant Leaf Disease" February 2012

[7] S. A. Ramesh Kumar, K. Ramesh Kumar "A Study on Paddy Crops Disease Prediction Using Data Mining Techniques" 2013 